\title{
Presentación
}

\section{Política(s), poder(es) y retos locales-globales}

Este número representa un gran desafío. En él ponemos a dialogar textos que empiezan a llegar a nuestra revista desde latitudes, disciplinas y narrativas bien diversas, y que, de paso, vienen con inmensos retos para los estudiosos de lo social en las Américas. Retos que nos invitan, que nos empujan, a leer entre líneas, a interpretar y analizar conexiones, tendencias y evidencias que surgen en dinámicas no sólo diversas y complejas, sino diversificadas y complejizadas por las mismas prácticas de los analistas de las humanidades y las ciencias sociales.

La colección de artículos que van a ver a continuación proponen fascinantes recorridos, al estilo de La Rayuela de Julio Cortazar, por tiempos, lugares y agentes muy diversos en las Américas. En este sentido, les proponemos arrancar por el Pacífico colombiano, y encontrarse con una explicación del nacimiento de un particular campesinado negro, que se forjó en medio del final de la esclavitud y de los inicios del precario Estado-nación de Colombia.

En Libertad en la selva. La formación de un campesinado negro en el Pacífico colombiano, 1850-1930, Claudia María Leal León, sostiene que la liberación de los esclavos en el pacífico no sólo permitió el acceso a la tierra, sino la formación de un campesinado vinculado a las economías extractivas de comienzos del siglo pasado. Su libertad vino con un alto grado de autonomía y de poder, ganado por el control del territorio (selvático, húmedo, y rico en recursos mineros), y por la marginalidad económica de esta región.

De allí, los invitamos a saltar al sur del continente, y conocer sobre las trayectorias económicas y políticas de los terratenientes chilenos durante el siglo anterior, confrontados a cambios económicos y políticos de carácter internacional y local. La versión confeccionada por Octavio Avendaño y María Cristina Escudero en Elitismo y poder gremial en la Sociedad Nacional de Agricultura (SNA) permite observar que, a pesar de la acelerada modernización que enfrentaron los hacendados en Chile desde los años 60, ellos han logrado mantener su poder e incidencia política, mediante las organizaciones gremiales. 
Los autores sostienen que, a pesar de los cambios tanto en el sector rural como el contexto político, la Sociedad Nacional de Agricultura (SNA) ha demostrado gran capacidad para adoptar su estructura y liderazgo, así como para representar los interese de esta élite económica e influir en las políticas agrarias en Chile.

A pesar del salto geográfico y temporal que implica nuestra tercera escala, aquí se pueden observar cómo los poderes económicos y políticos de campesinos negros y de élites agrarias, en Colombia y Chile, respectivamente, corresponderían con los conceptos de sociedades abiertas planteados por Karl Popper. Los ejemplos de estos dos casos de democracias muestran, en la práctica, la presencia de más valores, más visiones del mundo (filosóficas y religiosas), y más propuestas y organizaciones políticas, tal y como lo ambicionaba el filósofo austriaco.

En La propuesta que tal vez hubiera impulsado Karl Popper ante los enemigos de la sociedad abierta de hoy: para el Siglo XXI, el reformismo, Juan Guillermo Estay Sepúlveda y Mario Lagomarsino Montoya, sostienen que mientras las principales angustias de Popper estaban en los giros que se dieron en el mundo hacia el totalitarismo y hacia una reacción más tribal hace varias décadas, hoy quizá, en un mundo multicultural, las principales preocupaciones del filósofo quizá estarían en el fundamentalismo. Tendencias todas que no solo atentan contra la libertad, sino que aspiran a convertir al ser humano den una suerte de engranaje en supuestos sistemas ideales y perfectos.

Las anteriores experiencias de diversidad, poder, multiculturalidad y política, empatan bien con las situaciones que experimentan migrantes latinos en países del Norte de América cuando se enfrentan a la movilidad de sus territorios, culturas, economías y simbologías. Las comunicaciones y la información que gravitan y se forman en las redes tecnológicas se entretejen en la vida de los migrantes para, en unos casos, aliviar, y en otros, deteriorar, sus intentos, por cruzar las fronteras de los Estados y por hacerse parte de otros territorios y naciones.

$\mathrm{El}$ artículo Vulnerabilidad y prácticas de información: experiencias de migrantes latinos (indocumentados) en EE.UU., de Ricardo Gómez, nos lleva a la frontera de México con los Estados Unidos, y de allí hacia el norte hasta llegar a Seattle, para mostrar como la pobreza de información que viven los inmigrantes indocumentados en la frontera se va ampliando a medida que la vulnerabilidad y la incertidumbre se van superando con el establecimiento paulatino en sus lugares de destino. Sin embargo, la vulnerabilidad no se acaba completamente, ni el sentido de transitoriedad, dado el riesgo permanente de ser deportados y las condiciones precarias de empleo.

De las experiencias que enfrentan los migrantes latinos en Norte América, les proponemos retornar a Cali, Colombia, para conocer las privaciones y obstáculos que enfrentan otro tipo de migrantes. En este caso se trata de personas 
del Pacífico colombiano que han sido forzadas a desplazarse por el conflicto político armado.

En su texto En la base de la ruta: barreras de acceso y estrategias de atención en la ruta de declaración y registro de víctimas del conflicto, Gabriela Recalde Castañeda, nos permite observar la complejidad en las interacciones entre las víctimas del desplazamiento y el Estado colombiano, encarnado en funcionarios públicos, para comprender el origen de los obstáculos que enfrenta la población desplazada para acceder a sus derechos a la verdad, a la justicia y la reparación. A través de un estudio de caso del Sistema Nacional de Atención y Reparación a Víctimas (SNARIV) en Cali, la autora sostiene que las barreras de acceso son una forma “artesanal" o empírica, no sistemática, para hacer frente a la la sobredemanda y la falta de recursos para brindar una atención integral a las víctimas del conflicto. También, que las actitudes empáticas de los funcionarios con las víctimas, son formas de suplir la poca o nula capacitación de funcionarios para una tarea tan compleja como esta.

Finalmente, este viaje nos lleva a planos y dimensiones de otro tipo que empatan con la incertidumbre, el miedo y el silenciamiento que enfrentan los migrantes nacionales e internacionales, tanto los que lo hacen por decisión propia, como aquellos que son forzados a moverse a otros lugares, tiempos y culturas. En el último texto nos veremos exigidos a realizar un recorrido que apunta a la construcción de una poética del silencio para la narrativa hispanoamericana. El recorrido, incluye un análisis de los recursos de estilo y retórica utilizados por algunos autores en su intento por escribir sobre el silencio. De igual manera pasa por el examen de los rastros que hay en los textos frente a la capacidad o incapacidad de la palabra para dar cuenta del silencio, y por el reconocimiento de la conciencia de los escritores frente al mismo (silencio).

En Hacia una retórica y una poética del silencio, Juan Manuel Ramírez Rave, muestra lo largo y difícil del recorrido que ha propuesto, argumentando tanto la imposibilidad del lenguaje como el fracaso de la palabra para descifrar una realidad inefable como el silencio, "porque las palabras han perdido su valor y paulatinamente se ha desplazado su poder”.

\section{Luis Fernando Barón}

Diciembre, 2016 